\title{
Mechanical properties of polypropylene mesh used in pelvic floor repair
}

\author{
J. S. Afonso • P. A. L. S. Martins • M. J. B. C. Girao • \\ R. M. Natal Jorge • A. J. M. Ferreira - T. Mascarenhas • \\ A. A. Fernandes • J. Bernardes - E. C. Baracat • \\ G. Rodrigues de Lima $\cdot$ B. Patricio
}

Published online: 4 December 2007

(C) International Urogynecology Journal 2007

\section{Erratum to: Int Urogynecol J}

DOI 10.1007/s00192-007-0446-1

In the section "Materials and methods" (second paragraph, fifth sentence), the displacement rate was mistakenly given in millimeters per second instead of millimeters per minute. The correct sentence is:

"All the samples were tested with a constant displacement rate of $5 \mathrm{~mm} / \mathrm{min}$ in a mechanical testing machine specially designed for low-load soft-tissue testing [12]."

The online version of the original article can be found at http://dx.doi. org/10.1007/s00192-007-0446-1.

J. S. Afonso $(\bowtie) \cdot$ M. J. B. C. Girao • E. C. Baracat

G. Rodrigues de Lima

Department of Gynecology, Federal University of São Paulo,

São Paulo, Brazil

e-mail: afonso@histeroscopia.med.br

P. A. L. S. Martins - R. M. N. Jorge - A. A. Fernandes

Institute of Mechanical Engineering (IDMEC),

University of Porto,

Porto, Portugal

\author{
A. J. M. Ferreira \\ Department of Mechanical Engineering and \\ Industrial Management (DEMEGI), \\ University of Porto, \\ Porto, Portugal \\ T. Mascarenhas $\cdot$ J. Bernardes $\cdot$ B. Patricio \\ Department of Gynecology, Faculty of Medicine, \\ University of Porto, \\ Porto, Portugal
}

